\title{
Editorial
}

Liam M. Heaney

\section{Advancements in mass spectrometry as a tool for clinical analysis: part II}

https://doi.org/10.1515/cclm-2020-0259

Welcome to the second and final part of the special issue on Advancements in Mass Spectrometry as a Tool for Clinical Analysis. Part I addressed perhaps the more traditional themes of mass spectrometry (MS) in the clinical laboratory, notably for toxicological assessments and quantitative analysis of small molecules [1]. In this, part II, we diverge our interests into complex biological profiling, including large protein analyses as well as discoverybased 'omics investigations. We will also consider the current and future potential of MS in imaging science. Finally, we gain some insight into the possibility of automated MS for clinical workflows. The four main themes included in this issue are:

\section{Quantitative protein assessment}

Assessment of protein levels for clinical workflows has long been performed using immunometric, turbidimetric and nephelometric techniques, typically performed by a multi-purpose clinical chemistry autoanalyzer $[2,3]$. Measurement of specific proteins by MS can require extensive development, most notably when considering the behavior of and interferences to intact proteins in both the chromatographic and ionization spaces [4]. Nonetheless, the specificity provided by MS offers huge potential to explore the extensive complexity of the human proteome [5], as well for the development and measurement of novel protein biomarkers. Nedelkov and $\mathrm{Yu}$ [6] showcase some of the advantages of MS with discussion of apolipoprotein C-III proteoform measurements. This is followed by two original research articles. The first addresses the improved measurement of therapeutic monoclonal antibodies applying a middle-up protein subunit approach [7]. The second demonstrates the potential application of inductively coupled plasma-MS (ICP-MS) for clinical measurement of carcinoembryonic antigen through a europium-tagged immunolabeling approach [8].

\section{MALDI-MS for the clinic}

Matrix-assisted laser desorption ionization-MS, or commonly known as MALDI-MS, has been the subject of increasing interest over recent years, mainly owing to the improvements in mass spectral and spatial resolution afforded by modern instrumentation. In this section, we present three review articles that discuss the potential for MALDI-MS as a routine clinical biomarker technology [9], alongside its applications as an imaging technique for fracture healing [10] and cellular-level measurements [11]. In addition to these, Lellmen and Cramer [12] present original research into the application of liquid atmospheric pressure-MALDI-MS to identify bacteria based on the measurement of unique lipid profiles.

\section{Clinical application of 'omics technologies}

MS has afforded a wide range of new applications that have expanded on traditional 'omics technologies, such as those used for genomic sequencing [13]. In this section, we begin with Dr. Misra discussing his thoughts and views on the potential pathways and hurdles for use of an individualized metabolomics approach for clinical biomarker measurements [14]. Further opinion pieces are then presented for discussion on clinical proteomic amyloid typing [15], and within the interesting field of the human volatilome and the potential to combine canine and electronic 'sniffing devices' for clinical monitoring [16]. These thought-provoking opinion articles are supported by original research investigations into 
the utility of proteomics in the diagnosis of inflammatory bowel diseases [17], and the exploration of prostate cancer biology [18].

\section{Laboratory automation and kit-based approaches}

MS is a complex field and acquiring expertise in the development and application of biomarker assays requires many years of advanced training. The talented pool of scientists knowledgeable in MS cannot be replaced entirely by non-expert users. However, the field is working toward streamlining and improving reproducibility for repeated laboratory protocols using automated processes. Salvagno et al. [19] discuss the opportunities and challenges faced with the prospect of automated MS analyses, with additional comments from Le Goff and colleagues [20] regarding the pros and cons of applying MS processes with homemade or ready-to-use kit-based approaches. Finally, this section is rounded up with the investigation into the use of a fully automated liquid chromatography (LC)-MS system for 25-hydroxy vitamin D measurements [21].

This concludes the special issue on MS. It has been a delight to serve as Guest Editor for this project and I would like to again thank the authors and reviewers for their time and efforts. We sincerely hope you enjoy the articles published in this special issue. I encourage all who perform research in clinical MS to continue the excellent progress being made, and eagerly encourage readers to submit their future work to Clinical Chemistry and Laboratory Medicine.

Author contributions: The author has accepted responsibility for the entire content of this submitted manuscript. Research funding: None declared. Employment or leadership: None declared. Honorarium: None declared.

\section{References}

1. Heaney LM. Advancements in mass spectrometry as a tool for clinical analysis: part I. Clin Chem Lab Med 2020;58: 639-42.

2. Miller WL, Phelps MA, Wood CM, Schellenberger U, Van Le A, Perichon R, et al. Comparison of mass spectrometry and clinical assay measurements of circulating fragments of B-type natriuretic peptide in patients with chronic heart failure. Circ Heart Fail 2011;4:355-60.

3. Donato LJ, Snyder MR, Greene DN. Measuring and interpreting serum AAT concentration. Methods Mol Biol 2017;1639:21-32.

4. Donnelly DP, Rawlins CM, DeHart CJ, Fornelli L, Schachner LF, Lin $Z$, et al. Best practices and benchmarks for intact protein analysis for top-down mass spectrometry. Nat Methods 2019;16:587-94.

5. Aebersold R, Agar JN, Amster IJ, Baker MS, Bertozzi CR, Boja ES, et al. How many human proteoforms are there? Nat Chem Biol 2018;14:206-14.

6. Nedelkov D, Hu Y. Complexity, cost, and content - three important factors for translation of clinical protein mass spectrometry tests, and the case for apolipoprotein C-III proteoform testing. Clin Chem Lab Med 2020;58:858-63.

7. Cradic KW, Ladwig PM, Rivard AL, Katrangi W, Wintgens KF, Willrich MA. Vedolizumab quantitation using high-resolution accurate mass-mass spectrometry middle-up protein subunit: method validation. Clin Chem Lab Med 2020;58: 864-72.

8. Jiang W, Sun G, Wen X, Men S, Cui W, Jing M, et al. Development and evaluation of an element-tagged immunoassay coupled with inductively coupled plasma mass spectrometry detection: can we apply the new assay in the clinical laboratory? Clin Chem Lab Med 2020;58:873-82.

9. Israr MZ, Bernieh D, Salzano A, Cassambai S, Yazaki Y, Suzuki T. Matrix-assisted laser desorption ionisation (MALDI) mass spectrometry (MS): basics and clinical applications. Clin Chem Lab Med 2020;58:883-96.

10. Nauta SP, Poeze M, Heeren RM, Porta Siegel T. Clinical use of mass spectrometry (imaging) for hard tissue analysis in abnormal fracture healing. Clin Chem Lab Med 2020;58: 897-913.

11. Ščupáková K, Balluff B, Tressler C, Adelaja T, Heeren RM, Glunde $\mathrm{K}$, et al. Cellular resolution in clinical MALDI mass spectrometry imaging: the latest advancements and current challenges. Clin Chem Lab Med 2020;58:914-29.

12. Lellman SE, Cramer R. Bacterial identification by lipid profiling using liquid atmospheric pressure matrix-assisted laser desorption/ionization mass spectrometry. Clin Chem Lab Med 2020;58:930-38.

13. Hasin Y, Seldin M, Lusis A. Multi-omics approaches to disease. Genome Biol 2017;18:83.

14. Misra B. Individualized metabolomics: opportunities and challenges. Clin Chem Lab Med 2020;58:939-47.

15. Canetti D, Rendell NB, Gilbertson JA, Botcher N, Nocerino P, Blanco A, et al. Diagnostic amyloid proteomics: experience of the UK National Amyloidosis Centre. Clin Chem Lab Med 2020; 58:948-57.

16. Lippi G, Heaney LM. The "olfactory fingerprint": can diagnostics be improved by combining canine and digital noses? Clin Chem Lab Med 2020;58:958-67.

17. Basso D, Padoan A, D'Incà R, Arrigoni G, Scapellato ML, Contran $\mathrm{N}$, et al. Peptidomic and proteomic analysis of stool for diagnosing IBD and deciphering disease pathogenesis. Clin Chem Lab Med 2020;58:968-79.

18. Ross JA, Vissers JP, Nanda J, Stewart GD, Husi H, Habib FK, et al. The influence of hypoxia on the prostate cancer proteome. Clin Chem Lab Med 2020;58:980-93. 
19. Salvagno GL, Danese E, Lippi G. Mass spectrometry and total laboratory automation: opportunities and drawbacks. Clin Chem Lab Med 2020;58:994-1001.

20. Le Goff C, Farre-Segura J, Stojkovic V, Dufour P, Peeters S, Courtois J, et al. The pathway through LC-MS method development: in-house or ready-to-use kit-based methods? Clin Chem Lab Med 2020;58:1002-9.

21. Benton SC, Tetteh GK, Needham S-J, Mücke J, Sheppard L, Alderson S, et al. Evaluation of the 25-hydroxy vitamin D assay on a fully automated liquid chromatography mass spectrometry system, the Thermo Scientific Cascadion SM Clinical Analyzer with the Cascadion 25-hydroxy vitamin D assay in a routine clinical laboratory. Clin Chem Lab Med 2020;58:1010-7.

Dr. Liam M. Heaney School of Sport, Exercise and Health Sciences, Loughborough University, Loughborough LE11 3TU, UK, E-mail: L.M.Heaney2@Lboro.ac.uk. https://orcid.org/0000-0002-8791-0167 